\title{
Synchrotron radiation induced TXRF $\dagger$
}

\author{
C. Streli, ${ }^{* a}$ P. Wobrauschek, ${ }^{a}$ F. Meirer ${ }^{a}$ and G. Pepponi ${ }^{b}$ \\ Received 18th December 2007, Accepted 10th April 2008 \\ First published as an Advance Article on the web 6th May 2008 \\ DOI: $10.1039 / \mathrm{b} 719508 \mathrm{~g}$
}

The use of synchrotron radiation (SR) as an excitation source for total reflection X-ray fluorescence analysis (TXRF) offers several advantages over X-ray tube excitation. Detection limits in the fg range can be achieved with efficient excitation for low $\mathrm{Z}$ as well as high $\mathrm{Z}$ elements due to the features of synchrotron radiation and in particular the high brilliance in a wide spectral range and the linear polarization in the orbital plane. SR-TXRF is especially interesting for samples where only small sample masses are available. Lowest detection limits are typically achieved using multilayer monochromators since they exhibit a bandwidth of about $0.01 \Delta E / E$. Monochromators with smaller bandwidth like perfect crystals, reduce the intensity, but allow X-ray absorption spectroscopy (XAS) measurements in fluorescence mode for speciation and chemical characterisation at trace levels.

SR-TXRF is performed at various synchrotron radiation facilities. An historical overview is presented and recent setups and applications as well as some critical aspects are reviewed.

\section{Introduction}

Total reflection X-ray fluorescence analysis is a well established analytical technique for the detection of major, minor and trace elements $^{1-3}$ especially suited for samples, where only small specimen mass is available. Moreover TXRF can be used to investigate wafer surface contaminations or determine depth profiles in the near surface region and determine the implantation dose when using the angular dependence of the fluorescence signal. ${ }^{4}$ Detection limits achieved with X-ray tube excitation are in the range of 1 pg. ${ }^{5}$

If the detection limits are to be further improved it is helpful to look at the definition of the limits of detection (LD):

$$
\mathrm{LD}=\frac{3 \sqrt{N_{\mathrm{B}}}}{N_{\mathrm{N}}} m_{\text {sample }} \text { or } \mathrm{LD}=\frac{3 \sqrt{I_{\mathrm{B}}}}{S} \frac{1}{\sqrt{t}}
$$

${ }^{a}$ Atominstitut, Vienna University of Technology, Vienna, Austria. E-mail: streli@ati.ac.at

${ }^{b}$ Centre for Materials and Microsystems of the Fondazione Bruno Kessler-IRST, Povo, Trento, Italy

$\uparrow$ This paper is part of a JAAS themed issue on Synchrotron Radiation, with guest editors Alex von Bohlen and Metin Tolan. where, $N_{\mathrm{N}}$ are the net counts, $N_{\mathrm{B}}$ the background counts, $m_{\text {sample }}$ is the sample mass, $I_{\mathrm{B}}$ is the background intensity, $S$ is the sensitivity (net intensity $/ m_{\text {sample }}$ ) and $t$ is the measuring time.

One can easily see from eqn (1) that there are different ways of improving the detection limits, namely increasing the sensitivity $S\left(I_{\mathrm{N}} / m\right)$, reducing the background, and increasing the measuring time, which, however, is limited for practical reasons.

Besides using total reflection geometry for reducing the spectral background and doubling the fluorescence signal from the sample, a further possibility to reduce scatter contributions from the sample itself is the use of linearly polarized primary radiation. ${ }^{6,7}$ Due to the anisotropic emission characteristics of the scattered radiation based on the classical dipole oscillator emission it is advantageous to place a detector in such a position that only the isotropic emission of the fluorescence signal is detected. Hence the combination of TXRF with polarized radiation leads to a lower background. Moreover, the use of monochromatic primary radiation improves the background conditions because only photons of one energy can be scattered. An increase in sensitivity can be attained by using a tunable intense excitation source, enabling the exciting energy to be adjusted to just above the absorption edge of the element of interest.

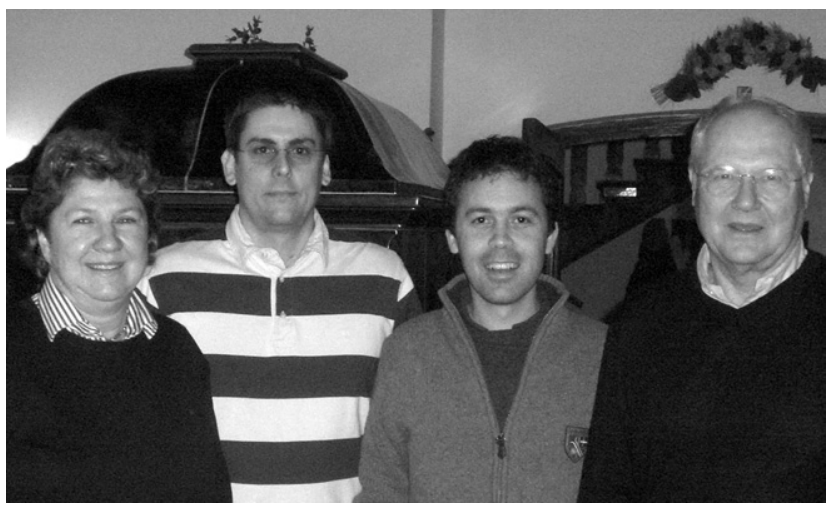

Christina Streli (far left) is Professor at the Atominstitut of the Vienna University of Technology, Austria. Her research interest is the development of special X-ray methods for interdisciplinary applications with the main focus using synchrotron radiation as the excitation source. Peter Wobrauschek (far right) is retired Professor at the Atominstitut working in the same group as Christina Streli. Florian Meirer (second from left) is undertaking his PhD in this group. Giancarlo Pepponi (second from right) is senior scientist at the Centre for Materials and Microsystems of the Fondazione Bruno Kessler-IRST in Trento, Italy. Since the attainment of his PhD in the group of Christina Streli in 2003, there has been a long term cooperation on SR-TXRF between the two groups. 
Synchrotron radiation with its outstanding properties has offered new possibilities for improving the power of TXRF. The intense beam with a continuous spectral distribution from photon energies in the infrared region to high energy photons as well as the linear polarization in the orbit plane and its natural collimation are features best suited for excitation in total reflection geometry.

For optimal excitation conditions the spectral distribution can be modified by elements like cut-off mirrors, monochromators and filters. Details can be found in ref. 8 .

Multilayer monochromators are best suited for XRF analysis. ${ }^{9,10}$ In comparison to crystal monochromators they offer a larger bandwidth $(\Delta E / E \approx 0.01)$, which leads to a much larger photon flux on the sample. Another advantage is the possibility of selecting the excitation energy just below a matrix element with high concentration and just above the absorption edge of the element of interest ("selective excitation"), with the possible drawback, however, of an increased background due to Raman scattering. ${ }^{11}$

If the experiments are performed in air, scattering of the exciting radiation contributes to the background. Therefore all measurements should be done in a vacuum chamber.

The combination of TXRF with synchrotron radiation may be performed with various geometrical arrangements for reflector and detector. Fig. 1 shows three possibilities.

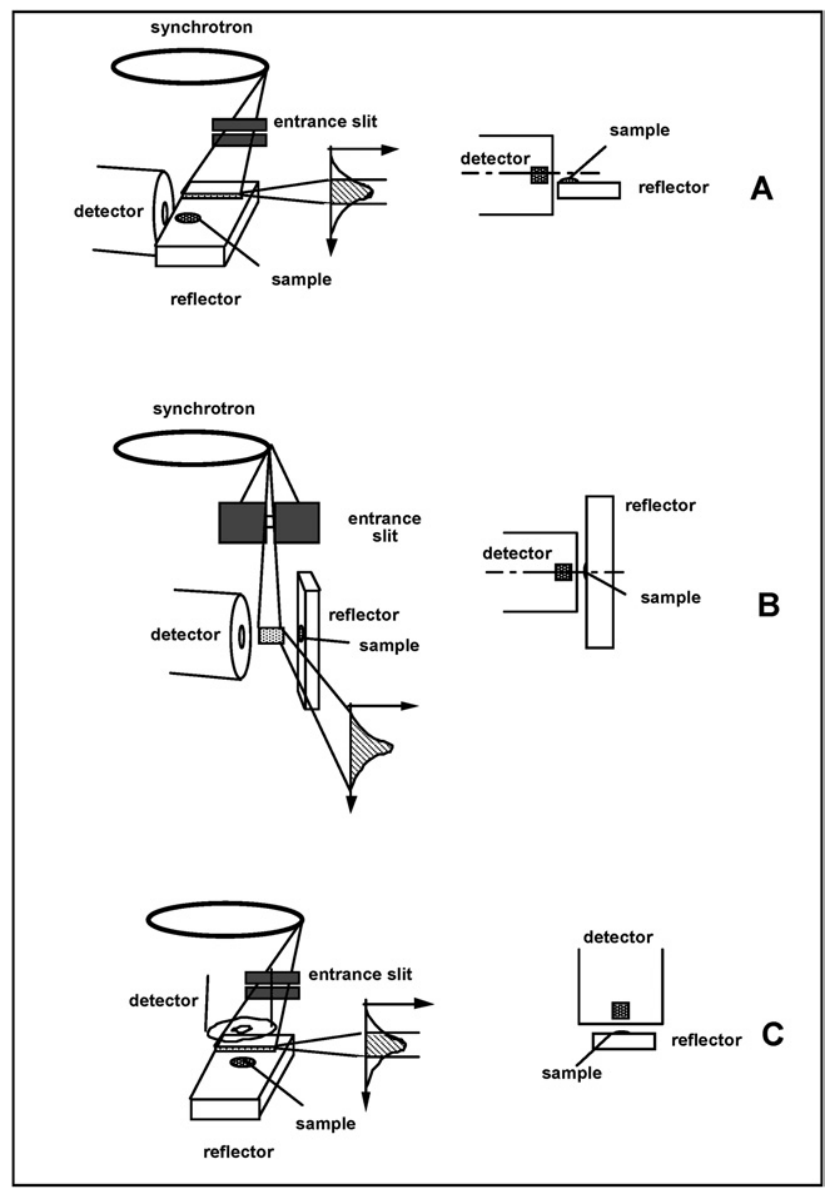

Fig. 1 Three possibilities of arranging wafer and detector for SRTXRF
For geometry A the polarization effect is fully utilized by positioning the detector axis in the plane of the orbit. Scattered radiation is not emitted in that direction. The sample is excited efficiently, and full homogenous illumination of the sample by the width of the beam in the horizontal plane is given. There are hardly any losses due to the collimators because the beam is naturally collimated in the vertical plane $(0.1$ to $0.2 \mathrm{mrad}$, depending on the energy). The detection of the fluorescence signal is not optimal because the detector must be sidelooking to use the polarization effect. The fluorescent radiation has a long path in the sample to reach the detector giving rise to absorption of the fluorescence in the sample and possible quantification errors.

The excitation conditions for the arrangement as displayed in Fig. 1B are poor. Most of the photons in the horizontal plane are absorbed in the collimation system. The intensity distribution and the degree of linear polarisation drop along the vertical axis when moving from the orbital plane and therefore the fluorescence intensity also drops with the deviation of sample regions from the plane of reference. Thus a restriction to $2 \mathrm{~mm}$ sample diameter is advisable due to the intensity and polarization distribution in the vertical plane. However the detection efficiency is high because of the large solid angle obtained due to the small distance between reflector and detector.

Excellent excitation and detection will be achieved with arrangement $\mathrm{C}$. This combination of sample-detector position though results in a complete loss of the use of the polarization effect. If the sample is small, which is the case in ultra trace analysis, the scattering contribution from the sample itself is negligible. Scattering from the substrate is reduced by total reflection.

\section{Historical review}

The first experiments were published by Iida et al. ${ }^{12}$ in 1986 performed at the Photon factory in Japan with a vertical reflector and sidelooking detector. As the used monochromator was $\mathrm{Si}$ 111 , the obtained detection limits were in the pg range, comparable with tube excitation. In 1988 Pella and Dobbyn ${ }^{13}$ published results from their experiments at NSLS using a horizontal reflector and a sidelooking detector.

The first experiments of the Atominstitut group were performed at SSRL, beamline 10-2 together with F. Hegedüs in 1991. The determination of transmutational elements like $\mathrm{Ni}$ in a $\mathrm{Cu}$ matrix after $\mathrm{p}+$ bombardement was the task. ${ }^{14} \mathrm{~A}$ crystal monochromator and a sidelooking detector geometry was used. The reflector was mounted vertically.

In 1994 Brennan et al. performed experiments at SSRL at a wiggler beamline-beamline $6-2 .{ }^{15}$ The main goal was to optimize the setup for Si wafer surface characterization. LD's of $1 \times 10^{8}$ atoms $\mathrm{cm}^{-2}$ have been achieved using a double ML-monochromator and a Teflon-filter ${ }^{16,17}$ to prevent saturation of the detector.

The first experiments at HASYLAB, DESY Hamburg, Beamline L, which is a bending magnet beamline, were performed by the Atominstitut group in 1994. The arrangement was a vertical reflector and sidelooking detector. Detailed information concerning the experiments are given in ref. 18 and 19. Detection limits for $\mathrm{Ni}$ with an excitation energy of $10 \mathrm{keV}$ 
were found to be $13 \mathrm{fg}$ or $1.3 \times 10^{8}$ atoms $\mathrm{cm}^{-2}$ for an inspected area of $1 \mathrm{~cm}^{2}$. A multilayer was used to monochromatize the beam and an $\mathrm{Al}$ filter was applied to prevent the detector being saturated by the Si signal. Also, comparison of the various geometries has been performed by the Atominstitut group. ${ }^{20}$ Pepponi et $a l .{ }^{21}$ compared the vertical and horizontal geometry for different kinds of samples and found that for samples with a strong scattering matrix the horizontal geometry provided better results; for samples with no matrix the vertical geometry provided better results. He also compared SR-TXRF with microanalysis on ultra-thin foils and found that TXRF obtained better detection limits..22

At the ESRF, the European Synchrotron Radiation Facility in Grenoble, a feasibility test in 1996 showed that third generation machines, as the fully dedicated and application oriented installations like ESRF are called nowadays, offer new possibilities for mapping the distribution of metallic contaminants over the wafer surface with a LD in the $10^{8}$ atoms $\mathrm{cm}^{-2}$ range. ${ }^{23} \mathrm{~A}$ dedicated setup for a $300 \mathrm{~mm}$ wafer analysis was built - details can be found in ref. 4-but the setup was not accepted by the semiconductor industry.

For the low $\mathrm{Z}$ elements the ideal source for efficient excitation is definitely synchrotron radiation due to its high intensity also in the low energy region. Experiments have been started with the work of Madden et al. in $1993^{24}$ at SSRL, Beamline III-4 with filtered white radiation. The Atominstitut group started their experiments also in 1993 at Beamline III-4 and investigated in the following years the spectral distribution and geometries. ${ }^{25-27}$ The best suitable beamline at SSRL turned out to be the bending magnet beamline BL 3-3 in combination with a multilayer monochromator. Details of the setup can be found in ref. 28 . Droplet samples were compared with spin coated wafer samples. ${ }^{29}$ Detection limits of about $60 \mathrm{fg}$ for $\mathrm{Na}$ were achieved. Angle scans showed different adsorption behavior for the elements $\mathrm{Al}, \mathrm{Mg}$ and $\mathrm{Na}$ in a multielement sample.

In 2000 Baur et al. ${ }^{11,30}$ performed experiments at Beamline III-4 on low Z elements investigating the resonant Raman effect on spectra from $\mathrm{Si}$ wafers excited with an energy just below the absorption edge of Si. The authors obtained $2.8 \times 10^{10}$ atoms $\mathrm{cm}^{-2}$ detection limits for $\mathrm{Al}$ on $\mathrm{Si}$ wafers.

In 1999 the ATI group started experiments at the plane grating monochromator beamline for undulator radiation of the Physikalisch-Technische Bundesanstalt (PTB) at BESSY2, Berlin, Germany. The beamline could also be operated in wiggler mode, so excitation of $\mathrm{Na}, \mathrm{Mg}$ and $\mathrm{Al}$ was possible, the detection limits obtained were in the low pg range. ${ }^{31}$ As this beamline is best suited for delivering a low energy $(<1 \mathrm{keV})$ beam with extremely high spectral purity, detection limits for $\mathrm{C}$ and $\mathrm{N}$ could be determined to be below $1 \mathrm{pg}$. Also, a comparison between the possible geometries has been performed, the vertical arrangement of the wafer and sidelooking detector turned out to provide better results. Details can be found in ref. 32. Low Z elements on Si wafers were measured,$^{33}$ droplet samples containing B were analyzed and detection limits of $3 \mathrm{ng}$ were achieved. In addition, samples of a $5 \mathrm{~nm}$ carbon monolayer and carbon-nickel-carbon multilayer on silicon wafers were measured simultaneously for thickness and density. Further studies on resonant Raman scattering were performed, especially with regard to the influence of the excitation energy, set below the absorption edge of silicon, on the spectral background affecting the low $\mathrm{Z}$ element (see ref. 33).

\section{Recent activities}

A vacuum SR-TXRF setup has been available since 2004 at HASYLAB, Beamline L, Hamburg, Germany. ${ }^{34}$ The TXRF vacuum chamber is exchangeable with the instrumentation of the microfocus setup at Beamline L, a bending magnet beamline. The translation and rotation stages of the microfocus setup can be directly used for adjustment. A sample loader for $30 \mathrm{~mm}$ circular sample reflector - arranged in the vertical-is available as well as a sample holder for Si wafers up to $100 \mathrm{~mm}$ diameter. For the $30 \mathrm{~mm}$ reflectors an 8 stage sample changer has been installed recently. ${ }^{35}$ Fig. 2 shows a spectrum obtained from a Ni sample - from this, detection limits of $8 \mathrm{fg}$ have been deduced. Details can be found in ref. 36. Using the Si 111 crystal monochromator available at beamline L, X-ray absorption near edge structure (XANES) investigations in total reflection geometry on trace elements are also feasible. The setup - now equipped with a $50 \mathrm{~mm}^{2} \mathrm{SDD}$ - is available for all users.

The SR-TXRF setup at NSLS, Campinas, Brazil is also operated in a vacuum chamber; white beam excitation of a bending magnet beamline as well as monochromatic radiation from Si 111 is used. ${ }^{37}$ The sample reflector is located vertically. Detection limits of $0.04 \mu \mathrm{g} \mathrm{ml}^{-1}$ are reported. Mainly environmental samples are analyzed.

The SR-TXRF setup at Bejing Synchrotron, Bejing, China, is operated in air using white beam excitation of a bending magnet beamline. ${ }^{38}$

A SR-TXRF setup for wafer surface analysis at the PTB Beamline at BESSY2, Berlin, Germany, has been designed by the Physikalisch-Technische Bundesanstalt. ${ }^{39}$ This beamline provides low energy radiation $(0.1 \mathrm{keV}$ and $1.9 \mathrm{keV})$ from an undulator monochromatized by a plane grating monochromator with high energy resolution. The instrument can handle up to a $300 \mathrm{~mm}$ wafer and is also suited for EDXRF analysis of thin structures deposited in silicon wafers. The most prominent features are a high vacuum load-lock combined with an equipment front end module and an UHV irradiation chamber with an electrostatic chuck mounted on an 8-axis manipulator.

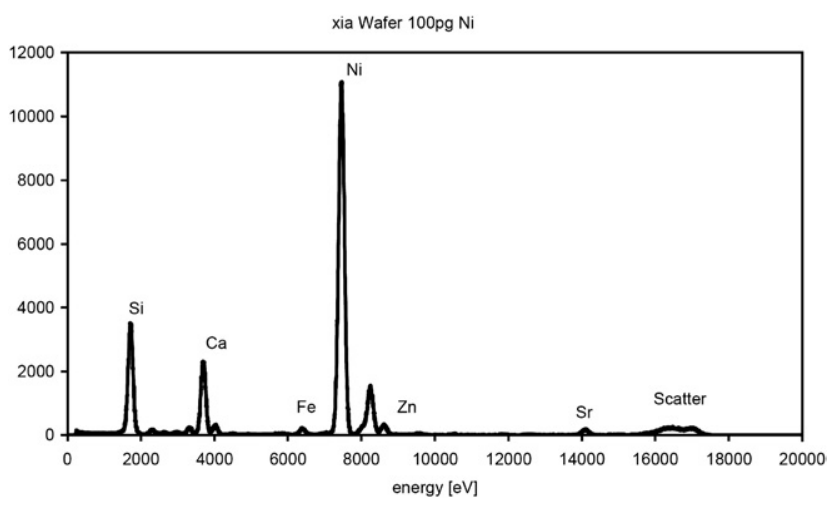

Fig. 2 Spectrum of a sample containing $100 \mathrm{pg}$ of Ni on a Si wafer as sample reflector excited with $17 \mathrm{keV}$ using the multilayer monochromator, lifetime: $60 \mathrm{~s}$, the detection was found to be $8 \mathrm{fg}(1000 \mathrm{~s})$, with a sensitivity of $340 \mathrm{cps} \mathrm{ng}^{-1} \mathrm{~mA}^{-1}$. 
The whole wafer surface of a 200 and a $300 \mathrm{~mm}$ wafer can be scanned. ${ }^{40}$ Recent activites report on detection limits below $100 \mathrm{fg}$ for $\mathrm{Al}$ and below $40 \mathrm{fg}$ for $\mathrm{Na}$. Also reference free quantification was performed successfully. ${ }^{41}$

A SR-TXRF setup for wafer analysis is also available at SSRL, Stanford, California. ${ }^{42}$ A vacuum chamber in a clean room environment has been installed at Beamline 6-2, a wiggler beamline suitable to analyze wafers up to $250 \mathrm{~mm}$ wafers. The beam is monochromatized by a double multilayer monochromator. The wafer is held by an electrostatic chuck mounted vertically, the detector is sidelooking and specially adapted to not get spurious peaks from the detector collimator. Detection limits of $1 \times 10^{8}$ atoms $\mathrm{cm}^{-2}$ for $\mathrm{Ni}$ are reported. The beamline is also equipped with a $\mathrm{Si} 111$ double crystal monochromator, so also absorption spectroscopy can be performed. No automatic wafer load lock is installed up to now, but cleanroom environment class 100 is established around the vacuum chamber. Recently the successful measurement of the elemental composition of material from the NASA Gemini mission to get information about the solar elemental abundances ${ }^{43}$ has been reported. Wafers were exposed to solar winds, the ions implanted in the wafer surface. Using angle dependence measurements the elemental composition could be determined.

SR-TXRF experiments with a wavelength dispersive (WD) spectrometer at SPring8, Harima, Japan, were described by Sakurai et al $^{44}$ At beamline 40XU, a helical undulator source with a Kirkpatrick-Baez (K-B) optic for focusing and high harmonic suppression is available. This quasi monochromatic radiation was used for TXRF followed by a Johansson-type spectrometer equipped with a Ge (220) curved analyzing crystal and with a YAP:Ce detector. The absolute and relative detection limit for nickel are $3.1 \times 10^{-16} \mathrm{~g}$ and $3.1 \mathrm{ppt}\left(\mathrm{pg} \mathrm{g}^{-1}\right)$ for a $0.1 \mu \mathrm{L}$ droplet of pure water, respectively, which is nearly 50 times better than the current best data achieved by conventional energydispersive TXRF using a $\mathrm{Si}(\mathrm{Li})$ detector system. Awaji et al. described a further WD setup at SPring8. ${ }^{45}$ At beamline 16XU, an undulator beamline, a Si 111 double crystal monochromator was used in combination with a Rh-coated focusing mirror to suppress the higher harmonics. The sample stage for wafer handling was taken from a Rigaku TXRF3000 spectrometer, from a load lock chamber. Kurunczi and Sakurai described a special method of sample preparation of water samples for WD-SRTXRF; they used HF etching to obtain a hydrophobic silicon surface and were able to produce a microdroplet of $80 \mu \mathrm{m} .^{46}$

\section{XAS measurements in TXRF geometry}

SR-TXRF was used for XAFS (X-ray absorption fine structure) measurements (i.e. NEXAFS (near edge X-ray absorption fine structure), XANES (X-ray absorption near edge structure) and EXAFS (extended X-ray absorption fine structure)) in fluorescence mode at various SR facilities which offers new possibilities of speciation on tiny sample amounts and low concentrations at trace levels. At Hamburg's HASYLAB, Beamline L, XAFS in fluorescence mode using total reflection geometry was compared with standard $45^{\circ}$ geometry and verified that the sensitivity in total reflection geometry was increased thereby lowering the accessible concentration range. ${ }^{47}$ Pepponi et al. ${ }^{48}$ reported
NEXAFS measurements of organic contaminants on silicon wafers that were performed at the PTB plane grating monochromator beamline for undulator radiation at the electron storage ring BESSYII. The $\mathrm{K}$ edges of $\mathrm{C}, \mathrm{N}$ and $\mathrm{O}$ were examined and speciation was performed. The same setup was used by Török et al. ${ }^{49}$ for NEXAFS measurements on nitrogen compounds in aerosol samples collected on silicon wafer surfaces. The detection limits in the low pg range for nitrogen allow analysis of samples collected in only 10 min with acceptable accuracy. Osán et al. ${ }^{50}$ used the PTB laboratory at BESSY, to apply the SR-TXRF-XANES technique to low Z elements. They reported the ammonium to nitrate ratio in Antarctic fine aerosols collected from less than $2 \mathrm{~m}^{3}$ of air. For Antarctic fine aerosols in the size range of $0.25-0.5 \mu \mathrm{m}$, nitrogen was observed to be present almost entirely as the ammonium species. When the size of aerosol particles increased in the range of $0.25-2 \mu \mathrm{m}$, the content of ammonium decreased and that of nitrate increased.

Streli et al. ${ }^{36}$ used this combination of techniques for arsenic speciation $\left(\mathrm{As}^{\mathrm{III}}\right.$ and $\left.\mathrm{As} \mathrm{s}^{\mathrm{V}}\right)$ in xylem sap of cucumber plants and achieved very good detection limits of As of $170 \mathrm{ng} \mathrm{l}^{-1}$. Recently the results on As speciation in xylem sap of cucumber plants have been published by Meirer et al. ${ }^{51}$ Fig. 3 shows some XANES spectra.

Giubertoni et $a .^{52}$ and d'Acapito et $a .^{53}$ recently reported EXAFS measurements at the GILDA beamline under grazing incidence conditions for the characterization of dopants (local structure related to electrical activation) in $\mathrm{Si}$ wafers for the production of Ultra Shallow Junctions.

XANES studies of $\mathrm{Cu}$ on $\mathrm{Si}$ wafer surface have been performed by Singh et al. ${ }^{54}$ at SSRL Beamline 6-2.

\section{Applications}

The new applications are annually reviewed in the Atomic Spectrometry Updates: X-ray fluorescence spectroscopy ${ }^{55-57}$

\section{Environmental}

An interesting application is the analysis of aerosol samples collected in a Berner-impactor (12 stages) directly on Si wafers,

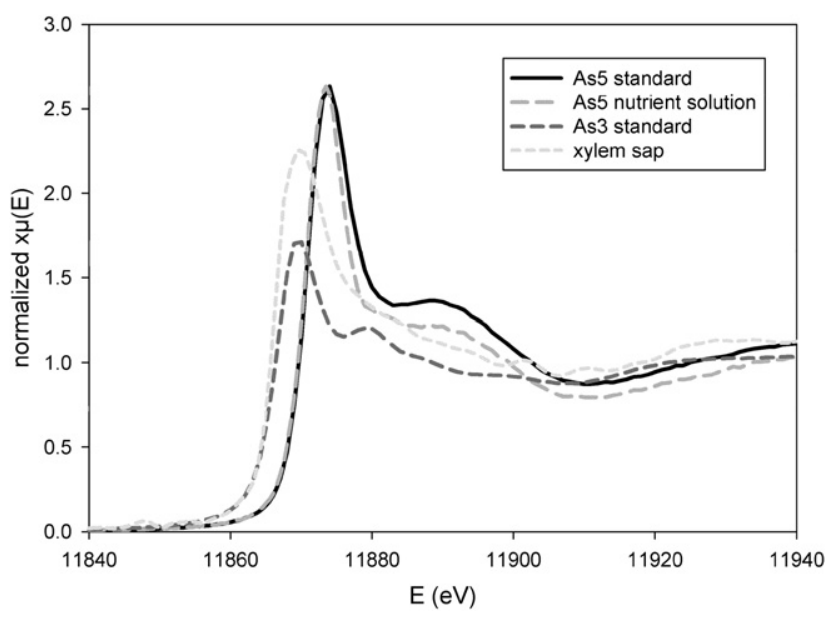

Fig. 3 XANES spectra of $\mathrm{As}^{\mathrm{v}}$ and $\mathrm{As}{ }^{\mathrm{III}}$ standard solutions, a nutrient solution containing $\mathrm{As}^{\mathrm{v}}$ and of xylem sap extracted from a cucumber plant. 
showing the advantage of the very low sample mass required for SR-TXRF. Experiments at Hasylab, Beamline L showed that $1 \mathrm{~h}$ sampling time was sufficient to get a reasonable signal - this will lead to detailed studies of air pollution. Fittschen et al. ${ }^{58}$ published a new technique for the deposition of standard solutions by inkjet printers and its applicability for aerosol analysis. Droplet sizes of 50-200 $\mu \mathrm{m}$ were achieved (which are smaller than the available synchrotron beam) and the authors reported an absolute calibration of the number of droplets versus measured Co intensity. These results lead to the conclusion that this technique is very promising for the quantification of aerosol samples collected by those impactors that produce a pattern and not a single spot. Groma et al. also performed measurements of aerosols, sampled with a May impactor, which collects the aerosols in the shape of a strip on $\mathrm{Si}$ wafers. ${ }^{59}$ The quantification was performed using a Cr strip as external standard. Detection limits of about $1 \mathrm{pg} \mathrm{m}^{-3}$ have been obtained for 20 min sampling time. Both groups drew attention to the considerable advantage of SR-TXRF for aerosol analysis in that a short collection time was sufficient to gather enough sample mass for analysis, to provide a means for monitoring of rapid changes in aerosol composition.

The SR-TXRF setup at the NSLS SR facility in Brazil was used for various applications: The determination of various elements in Brazilian wines, ${ }^{60}$ in several mineral waters commonly available in Brazil ${ }^{61}$ and in sea water after salt matrix removal with Pyrolidine-dithiocarbamate. ${ }^{62}$ Moreira et al. studied the metal absorption in culture corn irrigated with domestic sewage and found higher metal concentration in the plant irrigated with sewage than in the plant irrigated with water. Salvador et al. ${ }^{63}$ determined trace elements in various plants to perform environmental pollution control successfully. De Vives et al. ${ }^{64}$ analysed tree rings from samples of wood collected from a specific species, Caesalinia peotophoroides, which is common in Brazil in both urban and country areas. The samples were digested prior to measurement by TXRF and the authors found a decrease in the $\mathrm{K} / \mathrm{Ca}, \mathrm{K} / \mathrm{P}$ and $\mathrm{Pb} / \mathrm{Ca}$ ratios towards the bark. The same group reported the use of fish samples as environmental monitors and discussed the risks to human health by the ingestion of fish contaminated by metals and other toxic elements. ${ }^{65}$ The ability of Tillandsia (an epiphyte widely used as an atmospheric monitor) to accumulate heavy metals was successfully tested by Wannaz et al. ${ }^{66}$ to provenance atmospheric emission sources in Argentina. Espinoza-Quinones et al. ${ }^{67}$ compared PIXE with SR-TXRF analysing river water and found $\mathrm{As}, \mathrm{Cr}, \mathrm{Cu}$ and $\mathrm{Zn}$ to be above the limits recommended by environmental legislation.

\section{Industrial/biochemical}

The SR-TXRF setup for wafer analysis at $S S R L$ was used to determined Fe concentrations on silicon wafer surface after wet cleaning treatment by SR-TXRF, TOF-SIMS, lifetime and deep level transient spectroscopy using SR-TXRF as reference. ${ }^{68}$ Good correlations were found.

SR-TXRF at the Taiwan National Synchrotron radiation centre was applied by Chang et al. ${ }^{69}$ to study $\mathrm{SiO}_{2} / \mathrm{Ta}_{2} \mathrm{O}_{5}$ multilayer films on glass substrates.

Several topics have been investigated at the Brazilian Nation Synchrotron Light source in Campinas: Trace elements in different pharmaceutical forms of diclofenac sodium have been determined by Zucchi et $a l^{70}$ - differences in trace element content could be verified. Perspex, Kimfoil and Mylar were compared as substrates for the analysis of liquid samples by Poli et $a l .{ }^{71}$ They found that thin polymer foils produced less background, but unfortunately they did not compare their substrates with the commonly used quartz or Silicon reflectors. Novikova et $a .^{72}$ investigated the protective effect of xydiphone on membrane-bound enzyme damaged by lead ions. They determined the position of $\mathrm{Pb}$ ions within the molecular film by TXRF before and after the xydiphone treatment and found that xydiphone effectively eliminated the $\mathrm{Pb}$ ions incorporated in the Ca-ATPase molecules. $\mathrm{Al}_{2} \mathrm{O}_{3}$ ceramic powders were analysed by Peschel et $a l^{73}$ using the SR-TXRF facility at Hasylab. SR-TXRF was used to check the homogeneity of elemental distribution, which limited the precision of the measurements

\section{Clinical applications}

Canellas et al. ${ }^{74}$ determined trace and major elements in serum of patients with chronic myelogenous leukaemia (CML). They found that the concentrations of $\mathrm{Ca}, \mathrm{Cr}, \mathrm{Cu}, \mathrm{Fe}, \mathrm{Mn}, \mathrm{P}, \mathrm{Rb}$ and $\mathrm{S}$ differed significantly between groups of healthy and CML patients. Serpa et al. $^{75}$ studied cognitive impairment related to changes in elemental concentrations in the brain of old rats. Higher $\mathrm{Br}$ and $\mathrm{Cu}$ values were found in certain brain regions of the cognitively impaired group in comparison with the control group.

\section{Critical aspects}

Though the advantages of SR-TXRF dominate, there are some aspects which have to be considered critically: first of all there is a limitation of Synchrotron radiation facilities and only few of them offer a TXRF set-up. Beamtime has to be paid or a proposal has to be submitted, this has to be reviewed and beamtime has to be assigned, if the proposal is approved. So a detailed project planning in time and tasks has to be made in advance. A further critical aspect is requirements on the sample reflectors, they have to be flat and smooth, $\lambda / 20$, with $\lambda$ of visible light is a good measure for flatness, the roughness should not exceed $2 \mathrm{~nm}$. Specially polished quartz reflectors or silicon wafers are best suited. As the technique is very sensitive it will also detect contaminations of the sample reflectors easily and the preparation of a clean blank reflector is sometimes tricky and needs the expertise of chemists. This is especially an issue if the samples are collected on reflectors in advance and no checking of the cleanness with this sensitivity is possible, e.g. aerosol collection. A last drawback one has to consider is that absolute quantification is normally not possible and an internal standard is required.

\section{Conclusions}

SR-TXRF combines successfully the use of synchrotron radiation with the intrinsic advantages of TXRF offering low detection limits (fg) for small amounts of samples if the exciting synchrotron radiation is selected by means of a multilayer monochromator. Using crystal or plane grating monochromators also XAS measurements can be performed to obtain chemical information (oxidation state, compound, bonds, local 
structure) also at trace levels. Various beamlines at synchrotron radiation facilities offer SR-TXRF setups for users, for chemical analysis at Hasylab, Hamburg, ANKA, Karlsruhe, both Germany, LNLS, Campinas Brazil. Wafer surface analysis is performed at the plane grating monochromator beamline for undulator radiation of the PTB at BESSY in Berlin, and at SSRL, Stanford, California. At several other facilities SR-TXRF experiments are performed. Applications range from industrial applications like wafer surface analysis to environmental and clinical ones.

\section{References}

1 R. Klockenkämper, Total Reflection X-ray Fluorescence Analysis, Wiley-Interscience, 1 edition (Nov 15 1996) edn, 1997.

$2 \mathrm{R}$. Van Grieken and A. Markowicz, Handbook of X-Ray Spectrometry, Marcel Dekker, Inc (112001), 1993.

3 P. Wobrauschek, X-Ray Spectrom., 2007, 36, 289-300.

4 C. Streli, P. Wobrauschek, L. Fabry, S. Pahlke, F. Comin, R. Barrett, P. Pianetta, K. Lüning and B. Beckhoff, in Handbook of practical $X$-ray fluorescence analysis, ed. B. Beckhoff, B. Kanngiesser, N. Langhoff, R. Wedell and H. Wolff, Springer Heidelberg, Editon edn, 2006, pp. 498-553.

5 C. Streli, P. Wobrauschek, G. Pepponi and N. Zoeger, Spectrochim. Acta, Part B, 2004, 59, 1199-1203.

6 R. W. Ryon and J. D. Zahrt, in Handbook of X-ray Spectrometry, ed. R. Van Grieken and A. Markowicz, Marcel Dekker, Inc (112001), Editon edn, 1993, pp. 491-515.

$7 \mathrm{H}$. Aiginger, P. Wobrauschek and C. Brauner, Nucl. Instrum. Methods, 1974, 120, 541-542.

8 P. Wobrauschek and C. Streli, AIP Conf. Proc. 389, 1997, 389, 233248.

9 D. H. Bilderback, B. M. Lairson, T. W. Barbee, G. E. Ice and C. J. Sparks, Nucl. Instrum. Methods Phys. Res., 1983, 208, 251-261.

10 P. Pianetta and T. W. Barbee, Nucl. Instrum. Methods Phys. Res., Sect. A, 1988, 266, 441-446.

11 K. Baur, J. Kerner, S. Brennan, A. Singh and P. Pianetta, J. Appl. Phys., 2000, 88, 4642-4647.

12 A. Iida, A. Yoshinaga, K. Sakurai and Y. Gohshi, Anal. Chem., 1986, 58, 394-397.

13 P. A. Pella and R. C. Dobbyn, Anal. Chem., 1988, 60, 684-687.

14 F. Hegedüs, P. Wobrauschek, C. Streli, P. Winkler, R. Rieder, W. Ladisich, M. Victoria, R. W. Ryon and W. F. Sommer, X-Ray Spectrom., 1995, 24, 253-254.

15 S. Brennan, W. Tompkins, N. Takaura, P. Pianetta, S. S. Laderman, A. Fischer-Colbrie, J. B. Kortright, M. C. Madden and D. C. Wherry, Nucl. Instrum. Methods Phys. Res., Sect. A, 1994, 347, 417-421.

16 S. S. Laderman, J. Smith, A. Fischer-Colbrie, S. Brennan, W. Tompkins, N. Takaura, P. Pianetta, A. Shimazaki, K. Miyazaki, Y. Kaneko, N. Matsumura, J. B. Kortright, D. C. Wherry and M. Madden, SSRL Activity Report, 1994, P9074M.

17 P. Pianetta, N. Takaura, S. Brennan, W. Tompkins, S. S. Laderman, A. Fischer-Colbrie, A. Shimazaki, K. Miyazaki, M. Madden, D. C. Wherry and J. B. Kortright, Proceedings of the 5th international conference on synchrotron radiation instrumentation, Stony Brook, New York, USA, 1995.

18 R. Rieder, P. Wobrauschek, W. Ladisich, C. Streli, H. Aiginger, S. Garbe, G. Gaul, A. Knochel and F. Lechtenberg, Nucl. Instrum. Methods Phys. Res., Sect. A, 1995, 355, 648-653.

19 P. Wobrauschek, P. Kregsamer, W. Ladisich, R. Rieder and C. Streli, in Advances in X-Ray Analysis, ed. J. V. V. Gilfrich, I. C. Noyan, R. Jenkins, T. C. Huang, R. L. Snyder, D. K. Smith, M. A. Zaitz and P. K. Predecki, Springer US, ed. 1 (31.01.1998), Editon edn, 1997, vol. 39, pp. 755-767.

20 R. Görgl, P. Wobrauschek, P. Kregsamer, C. Streli, M. Haller, A. Knöchel and M. Radtke, X-Ray Spectrom., 1997, 26, 189-194.

21 G. Pepponi, C. Streli, P. Wobrauschek, S. Zamini, N. Zoger and G. Falkenberg, Spectrochim. Acta, Part B, 2003, 58, 2139-2144.

22 G. Pepponi, P. Wobrauschek, F. Hegedus, C. Streli, N. Zoger, C. Jokubonis, G. Falkenberg and H. Grimmer, Spectrochim. Acta, Part B, 2001, 56, 2063-2071.
23 L. Ortega, F. Comin, V. Formoso and A. Stierle, J. Synchrotron Radiat., 1998, 5, 1064-1066.

24 M. Madden, D. Wherry, P. Pianetta and S. Brennan, Mater. Res. Soc. Symp. Proc., 1993, 307, 125.

25 C. Streli, P. Wobrauschek, W. Ladisich, R. Rieder, H. Aiginger, R. W. Ryon and P. Pianetta, Nucl. Instrum. Methods Phys. Res., Sect. A, 1994, 345, 399-403.

26 C. Streli, P. Wobrauschek, V. Bauer, P. Kregsamer, R. Gorgl, P. Pianetta, R. Ryon, S. Pahlke and L. Fabry, Spectrochim. Acta, Part B, 1997, 52, 861-872.

27 C. Streli, P. Kregsamer, P. Wobrauschek, H. Gatterbauer, P. Pianetta, S. Pahlke, L. Fabry, L. Palmetshofer and M. Schmeling, Spectrochim. Acta, Part B, 1999, 54, 1433-1441.

28 C. Streli, P. Wobrauschek, P. Kregsamer, G. Pepponi, P. Pianetta, S. Pahlke and L. Fabry, Spectrochim. Acta, Part B, 2001, 56, 20852094.

29 C. Streli, G. Pepponi, P. Wobrauschek, N. Zoger, P. Pianetta, K. Baur, S. Pahlke, L. Fabry, C. Mantler, B. Kanngieer and W. Malzer, Spectrochim. Acta, Part B, 2003, 58, 2105-2112.

30 K. Baur, A. Singh, J. Wang, J. Kerner and P. Pianetta, in SRJ 99 Proceedings, 2000, p. 161.

31 C. Streli, P. Wobrauschek, B. Beckhoff, G. Ulm, L. Fabry and S. Pahlke, X-Ray Spectrom., 2001, 30, 24-31.

32 B. Beckhoff, R. Fliegauf, G. Ulm, G. Pepponi, C. Streli, P. Wobrauschek, L. Fabry and S. Pahlke, Spectrochim. Acta, Part $B, 2001,56,2073-2083$

33 C. Streli, G. Pepponi, P. Wobrauschek, B. Beckhoff, G. Ulm, S. Pahlke, L. Fabry, T. Ehmann, B. Kanngieer, W. Malzer and W. Jark, Spectrochim. Acta, Part B, 2003, 58, 2113-2121.

34 C. Streli, G. Pepponi, P. Wobrauschek, C. Jokubonis, G. Falkenberg and G. Zaray, X-Ray Spectrom., 2005, 34, 451-455.

35 F. Meirer, C. Streli, P. Wobrauschek, N. Zoeger, C. Jokubonis, G. Pepponi, G. Falkenberg, J. Osán, S. Toeroek, V. Groma, U. Fittschen, J. Broekaert, V. Mihucz, G. Zaray, V. Czech, J. Hofstaetter, P. Roschger and R. Simon, IAEA XRF Newsl., 2006, 12, 7-13.

36 C. Streli, G. Pepponi, P. Wobrauschek, C. Jokubonis, G. Falkenberg, G. Zaray, J. Broekaert, U. Fittschen and B. Peschel, Spectrochim. Acta, Part B, 2006, 61, 1129-1134.

37 C. A. Pérez, M. Radtke, H. J. Sánchez, H. Tolentino, R. T. Neuenshwander, W. Barg, M. Rubio, M. I. S. Bueno, I. M. Raimundo and J. J. R. Rohwedder, X-Ray Spectrom., 1999, 28, 320-326.

38 H. Yuying, W. Yingrong, Z. Limin, L. Guangcheng, H. Wei, Y. Lizhen, C. Jiapei, L. Jiangfu, Z. Tongcun and C. Enhua, Spectrochim. Acta, Part B, 2001, 56, 2057-2062.

39 B. Beckhoff, F. Fliegauf, J. Weser and G. Ulm, Ultra Clean Process. Silicon Surf. V, 2003, 92, 89-92.

40 B. Beckhoff, R. Fliegauf, G. Ulm, J. Weser, G. Pepponi, C. Streli, P. Wobrauschek, T. Ehmann, L. Fabry, C. Mantler, S. Pahlke, B. Kanngießer and W. Malzer, Electrochem. Soc. Proc., 2003, 03, $120-128$.

41 B. Beckhoff, R. Fliegauf, M. Kolbe, M. Muller, J. Weser and G. Ulm, Anal. Chem., 2007, 79, 7873-7882.

42 K. Baur, S. Brennan, P. Pianetta and R. Opila, Anal. Chem. A, 2002, 74(23), 608A-616A.

43 P. Pianetta, S. Brennan, K. Luening, H. Ishiii and D. Burnett, in TXRF conference 2007, Trento, Italy, Editon edn, 2007.

44 K. Sakurai, H. Eba, K. Inoue and N. Yagi, Anal. Chem., 2002, 74, $4532-4535$.

45 N. Awaji, Spectrochim. Acta, Part B, 2004, 59, 1133-1139.

46 S. Kurunczi and K. Sakurai, X-Ray Spectrom., 2005, 34, 56-58.

47 G. Falkenberg, G. Pepponi, C. Streli and P. Wobrauschek, Spectrochim. Acta, Part B, 2003, 58, 2239-2244.

48 G. Pepponi, B. Beckhoff, T. Ehmann, G. Ulm, C. Streli, L. Fabry, S. Pahlke and P. Wobrauschek, Spectrochim. Acta, Part B, 2003, 58, 2245-2253.

49 S. Török, J. Osán, B. Beckhoff and G. Ulm, Powder Diffr., 2004, 19(1), 81-86.

50 J. Osán, S. Török, B. Beckhoff, G. Ulm, H. Hwang, C. U. Ro, C. Abete and R. Fuoco, Atmos. Environ., 2006, 40(25), 4691-4702.

51 F. Meirer, G. Pepponi, C. Streli, P. Wobrauschek, V. G. Mihucz, G. Záray, V. Czech, J. A. C. Broekaert, U. E. A. Fittschen and G. Falkenberg, X-Ray Spectrom., 2007, 36, 408-412. 
52 D. Giubertoni, G. Pepponi, M. Bersani, S. Gennaro, F. D’Acapito, R. Doherty and M. A. Foad, Nucl. Instrum. Methods Phys. Res., Sect. B, 2006, 253, 9-12.

53 F. d'Acapito, S. Milita, A. Satta and L. Colombo, J. Appl. Phys., 2007, 102, 043524-043525.

54 A. Singh, K. Luening, S. Brennan, T. Homma, N. Kubo and P. Pianetta, Phys. Scr., 2005, 714.

55 P. J. Potts, A. T. Ellis, P. Kregsamer, C. Streli, C. Vanhoof, M. West and P. Wobrauschek, J. Anal. At. Spectrom., 2005, 20, 1124-1154.

56 P. J. Potts, A. T. Ellis, P. Kregsamer, C. Streli, C. Vanhoof, M. West and P. Wobrauschek, J. Anal. At. Spectrom., 2006, 21, 1076-1107.

57 M. West, A. T. Ellis, P. Kregsamer, P. J. Potts, C. Streli, C. Vanhoof and P. Wobrauschek, J. Anal. At. Spectrom., 2007, 22, 1304-1332.

58 U. E. A. Fittschen, S. Hauschild, M. A. Amberger, G. Lammel, C. Streli, S. Forster, P. Wobrauschek, C. Jokubonis, G. Pepponi, G. Falkenberg and J. A. C. Broekaert, Spectrochim. Acta, Part B, 2006, 61, 1098-1104.

59 V. Groma, F. Meirer, J. Osán, S. Toeroek, C. Streli, P. Wobrauschek and G. Falkenberg, Hasylab Annu. Rep., 2006, 2006, 1095-1096.

60 M. J. Anjos, R. T. Lopes, E. F. O. de Jesus, S. Moreira, R. C. Barroso and C. R. F. Castro, Spectrochim. Acta, Part B, 2003, 58, 2227-2232.

61 A. C. M. Costa, M. J. Anjos, S. Moreira, R. T. Lopes and E. F. O. de Jesus, Spectrochim. Acta, Part B, 2003, 58, 2199-2204.

62 A. C. M. Costa, M. J. Anjos, R. T. Lopes, C. A. Pérez and C. R. F. Castro, X-Ray Spectrom., 2005, 34, 183-188.

63 M. J. Salvador, S. Moreira, D. A. Dias and O. Zucchi, Instrum. Sci. Technol., 2004, 32(3), 321-333.

64 A. E. S. de Vives, S. Moreira, S. M. B. Brienza, J. G. S. Medeiros, M. T. Filho, O. L. A. D. Zucchi and V. F. d. N. Filho, Spectrochim. Acta, Part B, 2006, 61, 1170-1174.
65 A. E. S. Vives, S. Moreira, S. M. B. Brienza, O. Zucchi and V. F. Nascimento, J. Radioanal. Nucl. Chem., 2006, 270(1), 231-236. 66 E. D. Wannaz, H. A. Carreras, C. A. Perez and M. L. Pignata, Sci. Total Environ., 2006, 361(1-3), 267-278.

67 F. R. Espinoza-Quinones, S. M. Palacio, R. M. Galante, F. L. Rossi, D. C. Zenatti, I. R. A. Pereira, R. A. Welter, N. Rossi, C. L. Obregon, J. M. T. de Abreu, M. A. Rizzutto, N. Added and M. H. Tabacniks, Braz. J. Phys., 2005, 35(3B), 757-760.

68 D. Caputo, P. Bacciaglia, C. Carpanese, M. L. Polignano, P. Lazzeri, M. Bersani, L. Vanzetti, P. Pianetta and L. Moro, J. Electrochem. Soc., 2004, 151, G289-G296.

69 W. D. Chang, H. H. Hung, T. E. Dann, T. W. Huang and S. Y. Wu, Chin. J. Phys., 2004, 42(5), 607-618.

70 O. Zucchi, I. A. Schiavetto, M. J. Salvador and S. Moreira, Instrum. Sci. Technol., 2005, 33(2), 215-227.

71 V. S. Poli, M. H. Tabacniks, M. A. Rizzutto, N. Added, F. R. Espinoza-Quinones and S. M. Palacio, Braz. J. Phys., 2004, 34(3A), 970-972.

72 N. N. Novikova, E. A. Yurieva, S. I. Zheludeva, M. V. Kovalchuk, N. D. Stepina, A. L. Tolstikhina, R. V. Gaynutdinov, D. V. Urusova, T. A. Matkovskaya, A. M. Rubtsov, O. D. Lopina, A. I. Erko and O. V. Konovalov, J. Synchrotron Radiat., 2005, 12, 511-516.

73 B. U. Peschel, U. E. A. Fittschen, G. Pepponi, C. Jokubonis, C. Streli, P. Wobrauschek, G. Falkenberg and J. A. C. Broekaert, Anal. Bioanal. Chem., 2005, 382(8), 1958-1964.

74 C. G. L. Canellas, S. M. F. Carvalho, E. F. O. De Jesus, M. J. Anjos and R. T. Lopes, Radioanal. Nucl. Chem., 2006, 269(3), 631-634.

75 R. F. B. Serpa, E. F. O. de Jesus, M. J. Anjos, R. T. Lopes, M. G. T. do Carmo, M. S. Rocha, L. C. Rodrigues, S. Moreira and A. M. B. Martinez, Spectrochim. Acta, Part B, 2006, 61, 1219-1223. 